\title{
Effect of Alkali Concentration on Mechanical Properties, Microstructure, Zeta Potential and Electrical Conductivity of Thermally Cured Fly-Ash-Blast Furnace Slag Based Blended Geopolymer Composites
}

\author{
KUSHAL GHOSH ${ }^{1}$ and PARTHA GHOSH${ }^{2}$ \\ 1,2Department of Construction Engineering, Jadavpur University, Kolkata, India. \\ ${ }^{*}$ Corresponding E-mail: kushalghosh100@gmail.com \\ http://dx.doi.org/10.13005/ojc/340212
}

(Received: October 25, 2017; Accepted: January 20, 2017)

\begin{abstract}
A study has been made on Fly-ash- blast furnace slag blended geopolymer composite. Formation of an alumino silicate hydrate gel in presence of fly ash requires an activator solution of higher $\mathrm{pH}$ but formation of calcium silicate hydrate gel in presence of blast furnace slag requires an environment of lower $\mathrm{pH}$. Therefore, an attempt has been made to appreciate the role of alkali concentration to have a high performance Fly-ash-blast furnace slag blended geopolymer composite. The test samples have been subjected to a curing temperature of $60{ }^{\circ} \mathrm{C}$ and alkali content has been varied from $4 \%$ to $12 \%$, to appreciate the role of alkali concentration which fosters the growth of both type of gels. The reaction products and microstructure have been analyzed by SEM/EDAX, XRD and FTIR analysis. Zeta potential and electrical conductivity values have been also been studied to appreciate the colloidal stability of the blended composite under different alkali concentration.
\end{abstract}

Keywords: Fly ash, Slag, Geopolymer, Microstructure, Compressive strength, Water absorption, Bulk density, XRD, FTIR, SEM, Zeta Potential, Electrical Conductivity.

\section{INTRODUCTION}

Some research has been conducted on alkali activation of fly ash and ground granulated blast furnace slag(GGBS) ${ }^{1-6}$. In most of the cases either the fly ash or GGBS has been considered as the sole precursor though reaction products of the both are vastly different. The fly ash based alkali activated composites commonly known as geopolymers have a three dimensional polymeric gel network predominantly made of cation enabled aluminosilicate gel. The cation in most cases is sodium, which is available via the alkali activator used, which in most cases are sodium hydroxide, 
sodium silicate or a mixture of both. Ground granulated blast furnace slag on the other hand generates a calcium silicate hydrate gel. The preferred curing method of the fly ash and slag based composites are also different. Generally, heat and water curing being used for the fly ash and slag respectively. Among the two materials fly ash is being used more because of the fact that it is more easily available than slag. Fly ash based geopolymers have demonstrated very high acid, sulphate and thermal resistance ${ }^{7,8}$ which could be very useful in structural applications in extreme environments. But the hurdle in producing flyash based geopolymer composites with reasonably good mechanical properties, is the low reactivity of fly ash. In order to counter this specific problem ,researchers have used highly concentrated alkali activator solutions and have been fairly successful in producing geopolymer composites having compressive strengths ranging from 40-75 Mpa. But raising the concentration of the alkali activated solution raises the manufacturing costs substantially against manufacturing of sodium silicate is a very energy intensive process and as a result it lessens the impact of the geopolymer composites as a low energy green material ${ }^{9}$. Ground granulated blast furnace slag when subjected to alkali activation shows much higher initial reactivity than fly ash. It evident in terms of higher heat release and lower initial setting time also. It also leads to the usage of less concentrated alkali activated solutions. But in comparison to fly ash based geopolymer composites, ground granulated slag (GGBS) based composites exhibit lower durability characteristics like acid, sulphate and thermal resistance. The main reason for this being the calcium silicate hydrate based gel network which is very similar to the one exhibited by Portland cement based gel system. Thus in order to produce a geopolymer composite with a low energy footprint, high mechanical and superior durability properties a blended source material combining fly ash and ggbs, should be used. However, in order to produce a high performance blended geopolymer composite and to ascertain a unique mix design methodology which will be different from the ones being used for single source material based geopolymer composites. More investigations have to be made to appreciate the effect of synthesizing parameters like effect of concentration of alkaline activator solutions, water-binder ratio and curing temperature are of prime importance. This paper has attempted to highlight the effect of the various concentrations of sodium hydroxide on a thermally cured fly ash-GGBS based blended composites and to indicate an appropriate alkali concentration suitable for such composites. It has also tried to explain the nature of the reaction products which have been found to be a hybrid sodium alumino-calciumsilicate hydrate like polymeric gel. The research results have also indicated that formation of a proper polymeric gel structure does not occur at low alkali concentration ${ }^{10,11}$. Though addition of slag (GGBS) enhances the reactivity of the blended source material and only water curing will enable gel formation. However, thermal curing has been used for this study. The reason for this being that water curing of a fly ash- slag geopolymer composite gives rise to reaction products similar to that of an alkali activated slag composite ${ }^{12}$ and that hinders the durability related properties of the composite. Thermal curing should enable the geopolymer composite of a polymeric alumino silicate gel structure along with a calcium aluminosilicate gel displaying the superior durability characteristics than that of a fly ash based geopolymer composite and simultaneously exhibiting higher mechanical properties of a slag based composite. Specifically for this reason a separate study was conducted to determine the appropriate curing temperature for a fly ash-slag composite and a curing temperature of $60{ }^{\circ} \mathrm{C}$ was selected. This is incidentally lesser than the curing temperature of fly ash based geopolymer which is normally cured at $70-85^{\circ} \mathrm{C}^{13,14}$. The zeta potential which is an important factor in predicting the stability of a colloidal system has also been studied and the results indicate a clear relationship with the concentration of alkali activator. The electrical conductivity of the samples have also been reported and which can be a very important parameter in future studies predicting the corrosion resistance of reinforced geopolymer composites . There is an extreme scarcity of literature on thermally cured fly ash-slag blended geopolymer composites and this paper tries to address the effect of concentration of sodium hydroxide on its mechanical properties, reaction products, microstructure, colloidal stability as well as electrical conductivity in order to assess its importance and reliability as a blended geopolymeric source 
material using data regarding compressive strength, water absorption, apparent porosity, bulk density, ultrasonic pulse velocity, XRD, SEM-EDAX, FTIR, zeta potential analysis.

\section{EXPERIMENTAL PROCEDURE}

\section{Materials}

The geopolymer precursors used in this investigation were a fly ash (FA), Class $F$ according to ASTM C 618, from Kolaghat thermal power plant, West Bengal, India, and a granulated blast furnace slag (GBFS) supplied by Durgapur Steel plant, West Bengal, India. The oxide compositions of the precursors are given in Table 1. It is notable that the fly ash used is very low in calcium, which enables the development and analysis of calciumfree gel structures in the fly ash-based binder systems. The alkali activator was prepared by dissolution of sodium hydroxide pellets(Merck \& Co.) in water and then adding sodium silicate (49.1 wt.\% $\mathrm{SiO}_{2}$ and 50.9 wt.\% $\mathrm{Na}_{2} \mathrm{O}$, supplied by Loba Chemicals.) in the mix water, which was then allowed to cool to room temperature prior to preparation of the specimens. The activator doses used were $8 \mathrm{wt} \%$ by total mass of precursor as described in Table 1. All samples were formulated with a fly ash to slag ratio of $70: 30$, water/binder ratio of 0.38 , and cured at $60^{\circ} \mathrm{C}$. The samples were casted into $50 \mathrm{~mm} \times 50 \mathrm{~mm} \times 50 \mathrm{~mm}$ cubes. The mix ratio of 70:30 was taken on the basis of a previous study by this article's authors. The concerned study was on the effect of variation of slag on mechanical and microstructural properties of fly ash-slag and the 70:30 (flyash:slag) mix specimen was found to be the best performing mix formulation in terms of mechanical properties as well as microstructural characteristics.

Table 1: Mix proportions of the alkali-activated fly ash/slag geopolymer blends

\begin{tabular}{lccc}
\hline $\begin{array}{l}\text { Sample binder ratio } \\
\text { (wt.\% slag/ wt.\% fly ash) }\end{array}$ & $\begin{array}{c}\text { Fly-ash-Slag } \\
\text { Percentage }\end{array}$ & $\begin{array}{c}\text { Sodium metasilicate } \\
\text { (activator) (wt.\%) }\end{array}$ & $\begin{array}{c}\text { Sodium hydroxide } \\
\text { (activator) dose relative } \\
\text { to binder content (wt.\%) }\end{array}$ \\
\hline
\end{tabular}

$\begin{array}{lccc}\text { A1 } & 70-30 & 8 & 4 \\ \text { A2 } & 70-30 & 8 & 6 \\ \text { A3 } & 70-30 & 8 & 8 \\ \text { A4 } & 70-30 & 8 & 10 \\ \text { A5 } & 70-30 & 8 & 12\end{array}$

\section{Analytical techniques}

Microstructural and chemical analysis were performed on paste samples after an age of 7 days from the date of casting:: X-ray diffraction (XRD) using a Rigaku III instrument, scanning from $10 \%$ to $80 \% 2 \mathrm{~h}$, with a $0.02 \mathrm{~L}$ step size and 2 s/step count time.

Fourier transform infrared (FTIR) spectroscopy, using the $\mathrm{KBr}$ pellet method in a perkin elmer spectrometer 100 , scanning 32 times from 4000 to $400 \mathrm{~cm}^{-1}$ at $4 \mathrm{~cm}^{-1}$ resolution.

Field Electron Scanning Electron Microscopy (FESEM) with energy dispersive X-ray (EDX) analysis, at an accelerating volt-age of 10-20 kV using an (JEOL JSM-6700F)instrument. Zeta potential was measured using a Malvern Zetasizer.

Table 2: Chemical analysis by XRF (\%) of the solid binder precursors. LOI is loss on ignition at 1000 LC

\begin{tabular}{lcccccccccc}
\hline Oxide (wt.\%) & $\mathrm{SiO}_{2}$ & $\mathrm{Al}_{2} \mathrm{O}_{3}$ & $\mathrm{Fe}_{2} \mathrm{O}_{3}$ & $\mathrm{CaO}$ & $\mathrm{MgO}$ & $\mathrm{SO}_{3}$ & $\mathrm{Na}_{2} \mathrm{O}$ & $\mathrm{K}_{2} \mathrm{O}$ & LOI & Others \\
\hline Fly ash & 65.81 & 22.17 & 3.23 & 1.24 & 1.01 & 0.47 & 0.16 & 2.62 & 1.57 & 1.72 \\
Slag & 37.25 & 10.24 & 1.1 & 42.17 & 3.82 & 2.13 & 0.19 & .66 & 0.81 & 1.63 \\
\hline
\end{tabular}




\section{RESULTS AND DISCUSSION}

\section{Compressive Strength}

The compressive strength of the mix is seen to increase with the increase of alkali content.There is an exponential increase of $154.55 \%$ in the compressive strength of the A2 mix over A1. A3 mix reports an increase of $15.97 \%$ over the A2 mix. The A4 mix sees an decrease of compressive strength of $6.06 \%$ over the A3 mix. But the A5 mix has a decrease in strength of $37.149 \%$. $\mathrm{High} \mathrm{OH}-$ concentration in the solution accelerates the dissolution of $\mathrm{Si}^{4+}$ and $\mathrm{Al}^{3+}$ from precursors and acts as a reaction catalyst, while $\mathrm{Na}^{+}$serves as a charge balancing cation in the structure ${ }^{15,16,17}$. But high sodium hydroxide concentration leads to an increase of $\mathrm{pH}$ which hinders the leaching rate of $\mathrm{Ca}^{+}$ions. Thus at an optimum alkali concentration,in this case $8 \%$, Ca also contributes in the formation of andisordered structure with weak Al-O-Al bonds ${ }^{18}$. Presence of adequate $\mathrm{Ca}^{+}$ions in the gel framework can lead to the formation of phase-separated Alsubstitute calcium silicate hydrate $(\mathrm{C}-(\mathrm{A})-\mathrm{S}-\mathrm{H})$ and geopolymer ( $\mathrm{N}-\mathrm{A}-\mathrm{S}-\mathrm{H})$ gels. ${ }^{19,20}$ Studies have also shown that calcium content in alkali activated solid waste materials function extra sites of nucleation..$^{21,22}$ One of the reasons for the dissolution rate increasing with addition of alkali content (Van Jaarsveld and Van Deventer, 1999),that $\mathrm{Si}^{4+}$ and $\mathrm{Al}^{3+}$ species are released from the fly ash particle surface and into the solution increasing the thickness of the solution which in turn is the first step towards gelation stage of geopolymer. Thus from Van Jaarsveld and Van Deventer's findings they suggested that leaching was, therefore, dependent on alkali solution concentration. (1999). Rattanasak et al., studied the actual leaching rates of $\mathrm{Si}^{4+}$ and $\mathrm{Al}^{3+}$ ions and on an average $\mathrm{Si}^{4+}$ ion concentration close to $600 \mathrm{ppm}$ was obtained with $10 \mathrm{M} \mathrm{NaOH}$. For $5 \mathrm{M}$ and $15 \mathrm{M} \mathrm{NaOH}$, the concentrations were around approximately 200 and $260 \mathrm{ppm}$. At $5 \mathrm{M} \mathrm{NaOH}$, the dissolution happened at a lower rate due to decrease in base condition. As molarity was increased to $10 \mathrm{M} \mathrm{NaOH}$, the base condition was higher and the dissolution happened at a faster rate ${ }^{23}$. But at $15 \mathrm{M} \mathrm{NaOH}$, the dissolution was again reduced owing primarily to an increase in coagulation of silica ${ }^{24}$ which is also the case in this study where the compressive strength seems to decrease when the percentage of $\mathrm{NaOH}$ crosses $8 \%$ by weight of source material. Excess of $\mathrm{OH}^{-}$ions also causes a setback to the process of polycondensation which in turn has as a negative effect on the compressive strength ${ }^{25}$.

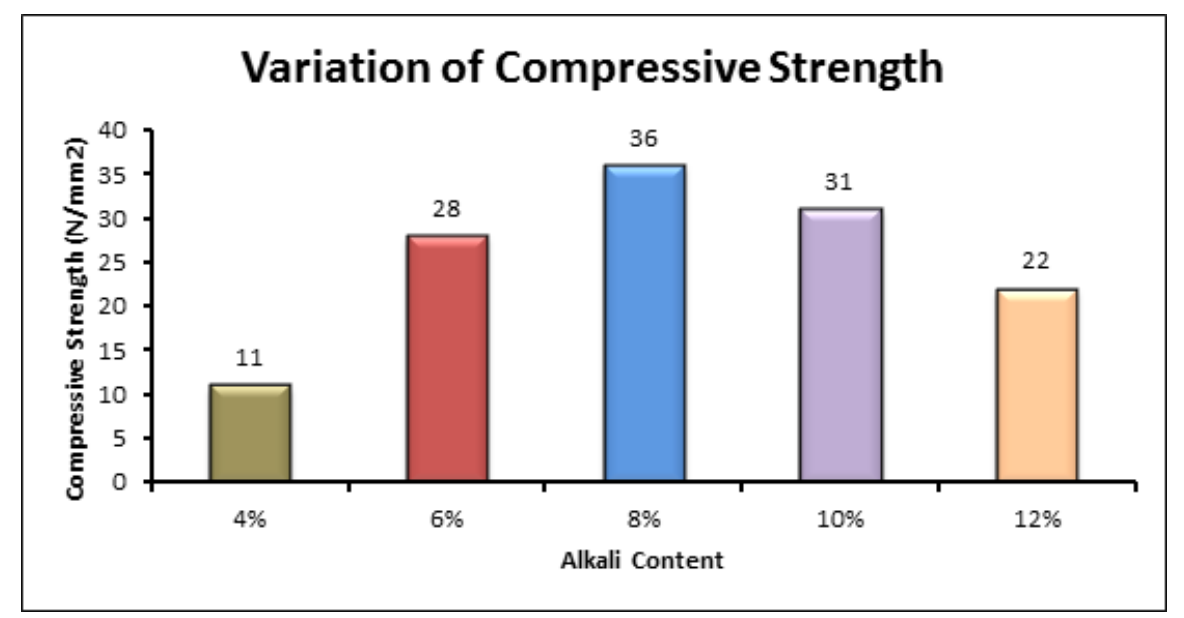

Fig. 1. Effect of variation of sodium hydroxide on compressive strength of fly ash slag based geopolymer composite

Bulk Density, Water Absorption, Apparent Porosity, Ultrasonic Pulse Velocity Test Results

The bulk density for the A1 mix with $4 \%$ $\mathrm{Na}_{2} \mathrm{O}$ is seen to have the lowest bulk density value at $1700.27 \mathrm{~kg} / \mathrm{m}^{3}$. The value increases to 1745.95 $\mathrm{kg} / \mathrm{m}^{3}$ for $\mathrm{A} 2$ mix with $6 \% \mathrm{Na}_{2} \mathrm{O}$ weight. The bulk density value for $A 3 \mathrm{mix}$ is higher at $1842.26 \mathrm{~kg} / \mathrm{m}^{3}$. It decreases slightly for A4 mix with $1837.95 \mathrm{~kg} / \mathrm{m}^{3}$ but it registers a steep drop for the A5 mix with a value of $1622 \mathrm{~kg} / \mathrm{m}^{3}$. Higher bulk density signifies 
closer packing of the molecules which in this case can be supported through the images of the microstructure which are in sync with the bulk density. The closer packing about the gel structure of the alkali activated flyash slag geopolymers can also be corroborated by the apparent porosity and water absorption results. The apparent porosity of the samples decreases with increase of alkali content upto the optimum level of $8 \%$. The lowest apparent porosity value was found to be at $4.71 \%$ for the A3 mix and the highest value was found for A5 mix at $14.23 \%$.Water absorption percentages for the different mixes followed the same trend with the $\mathrm{A} 1$ and $\mathrm{A} 4 \mathrm{mix}$ recording the highest and lowest values respectively. The changes in the above mentioned mechanical properties can be corroborated with UPV values as well. The UPV values of the A1, A2, A3, A4, A5 mix's are 3.56 $\mathrm{km} / \mathrm{sec}, 3.97 \mathrm{~km} / \mathrm{sec}, 4.10 \mathrm{~km} / \mathrm{sec}, 3.82 \mathrm{~km} / \mathrm{sec}$ and $3.33 \mathrm{~km} / \mathrm{sec}$ respectively. At low alkalinity neither the alumina, silica species from fly ash nor the calcium species from slag is sufficiently dissolved thus leading to lower mechanical properties From the micrographs it can be seen that addition of sodium hydroxide leads to the formation of a more homogenous geopolymer but upto the optimum content of $8 \%$. The calcium present in the composites acts as a seeding or precipitating element. The edax results also show that the calcium content risesupto A3 sample but starts decreasing there after thus reiterating the statement that high alkalinity obstructs the calcium from participating in the geopolymerisation reaction. The results signify that alkali content upto $8 \%$ is beneficial for the formation of a more cohesive microstructure in fly ash based geopolymers. The changes in gel network can be further explained with the FESEM images given in the FESEM/EDAX discussion analysis section.

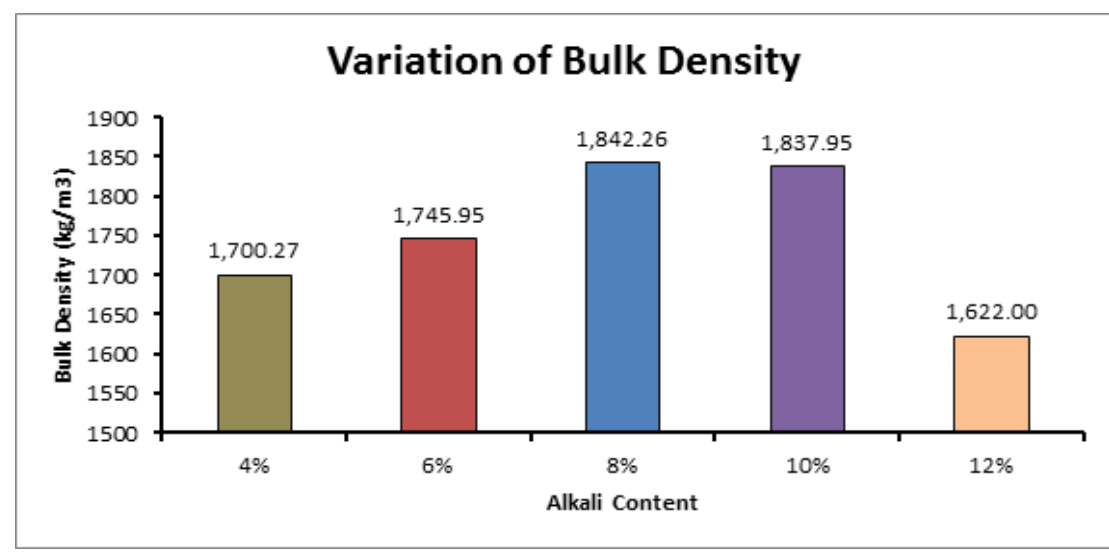

Fig. 2. Effect of variation of sodium hydroxide on bulk density of fly ash slag based geopolymer composite

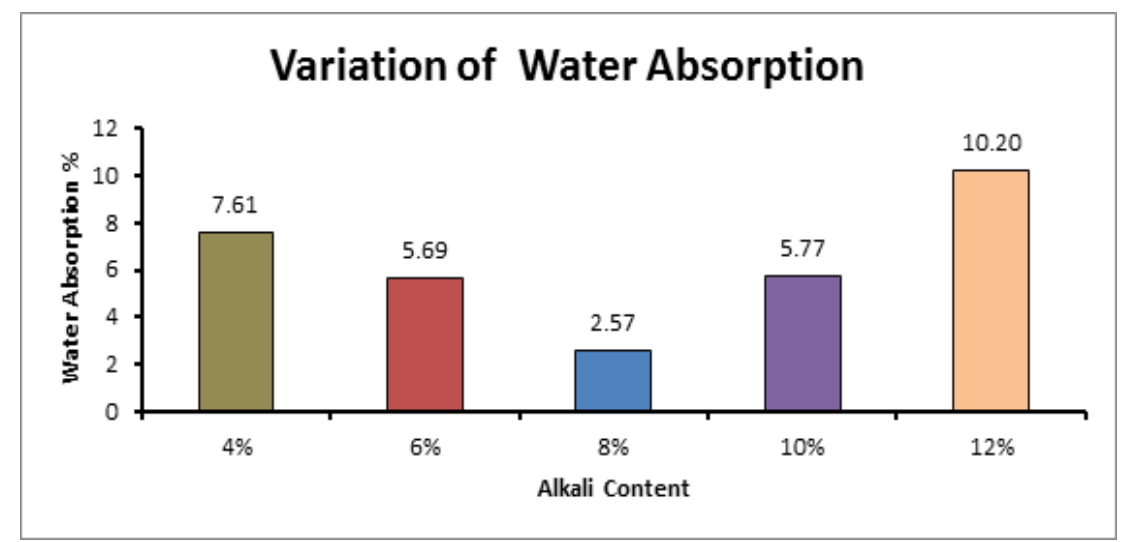

Fig. 3. Effect of variation of sodium hydroxide on water absorption of fly ash slag based geopolymer composite 


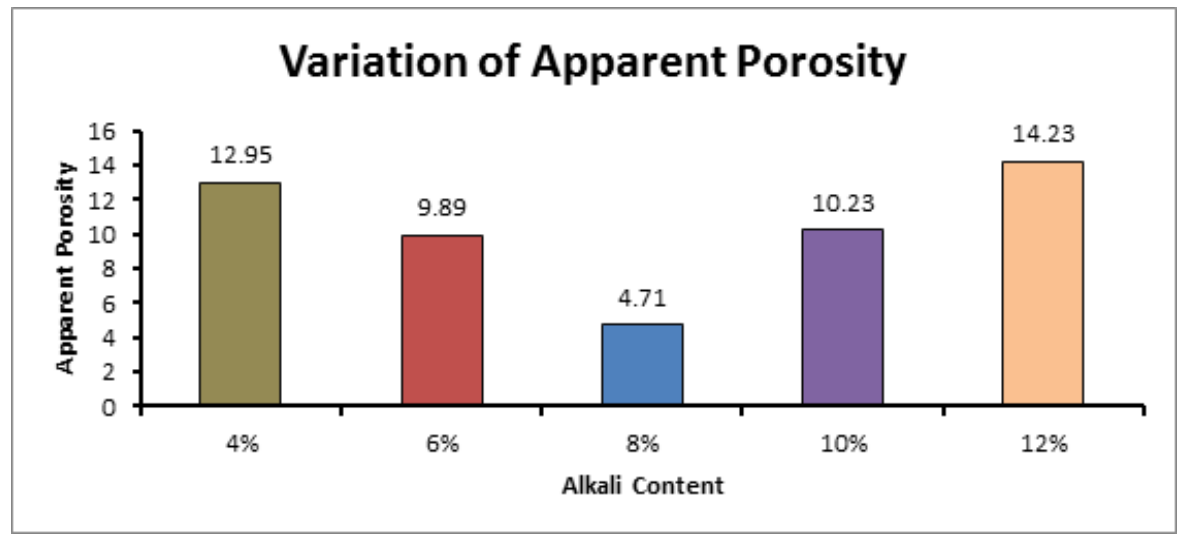

Fig. 4. Effect of variation of sodium hydroxide on apparent porosity of fly ash slag based geopolymer composite

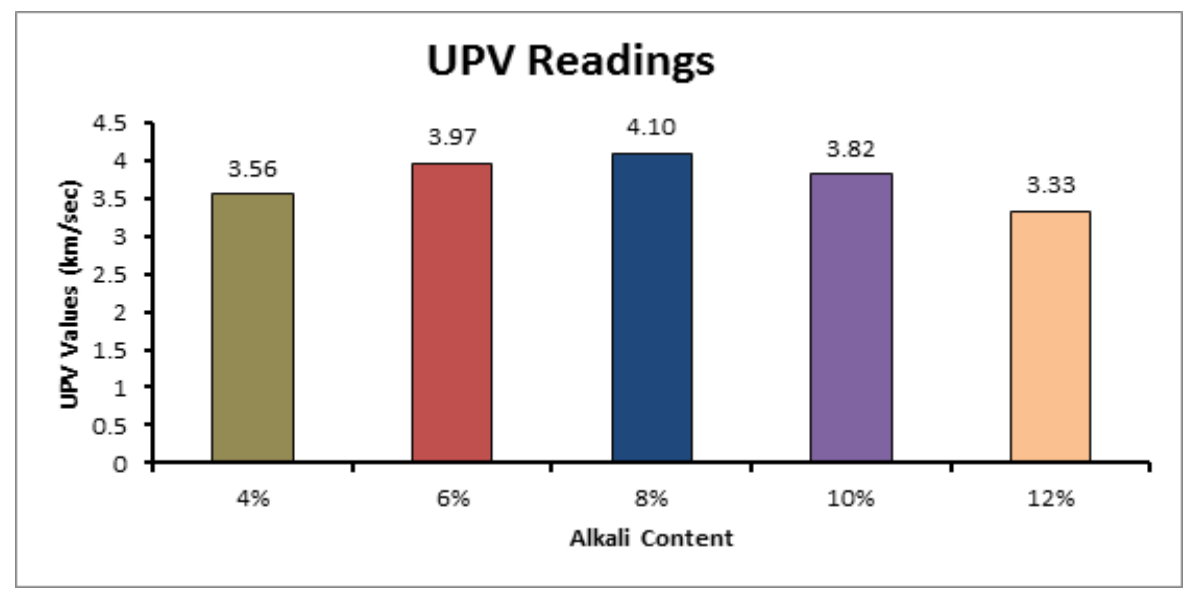

Fig. 5. Effect of variation of sodium hydroxide on ultrasonic pulse velocity readings of fly ash slag based geopolymer composite

\section{X - RAY diffraction analysis}

$X$ ray diffraction data of the $A 1$ mix suggests that the basic ingredients of fly ash such as quartz, mullite along with calcite due to the slag are present in it. But the data did not point to the presence of sialate,polysialate atoms that are the main products of geopolymerisation. In the A2 mix it was noticed that the in addition to the peaks of quartz and mullite, there were peaks denoting silimanite, an alumino silicate compound which signified improved level of geopolymerisation. In the A3 mix it can be seen that an alumino-calcium-silcate hydrate gel phase can be seen in the peaks. This phase is the result of high amount of cross linkage between the geopolymeric gel phase and calcium silicate hydrate gel phase e.g a product of the alkali activation of slag. As the percentage of alkali content increases in the A4 mix, the order of crosslinkage between the aluminum, silica and the calcium ions increases. As a result of this there are more peaks of cross linked alumina calcium silicate gel in the A4 mix than A3 mix. Analyzing the abovementioned peak diffraction data it can be seen as the percentage of sodium hydroxide is an integral factor controlling the process of geopolymerisation. Geopolymerisation can be divided into four stages (i) dissolution of $\mathrm{Si}$ and $\mathrm{Al}$ from the solid aluminosilicate materials in a strong alkaline aqueous solution, (ii) formation of Si and/or Si-Al oligomers in the aqueous phase, (iii) polycondensation of oligomers to form a three-dimensional aluminosilicate framework and (iv) bonding of the undissolved solid particles into the geopolymeric framework and hardening of the whole system into a final solid polymeric structure. And on closely monitoring the XRD data we can deduce that in the 
A1 mix due to inadequate $\mathrm{NaOH}$ concentration dissolution of the $\mathrm{Si}$ and $\mathrm{Al}$ ions did not take place properly thus hampering the progress of the subsequent stages. As the percentage of $\mathrm{NaOH}$ started increasing and reached an adequate amount in the A3 and A4 mix the first stage e.g dissolution of $\mathrm{Si}$ and $\mathrm{Al}$ ions was completed properly.

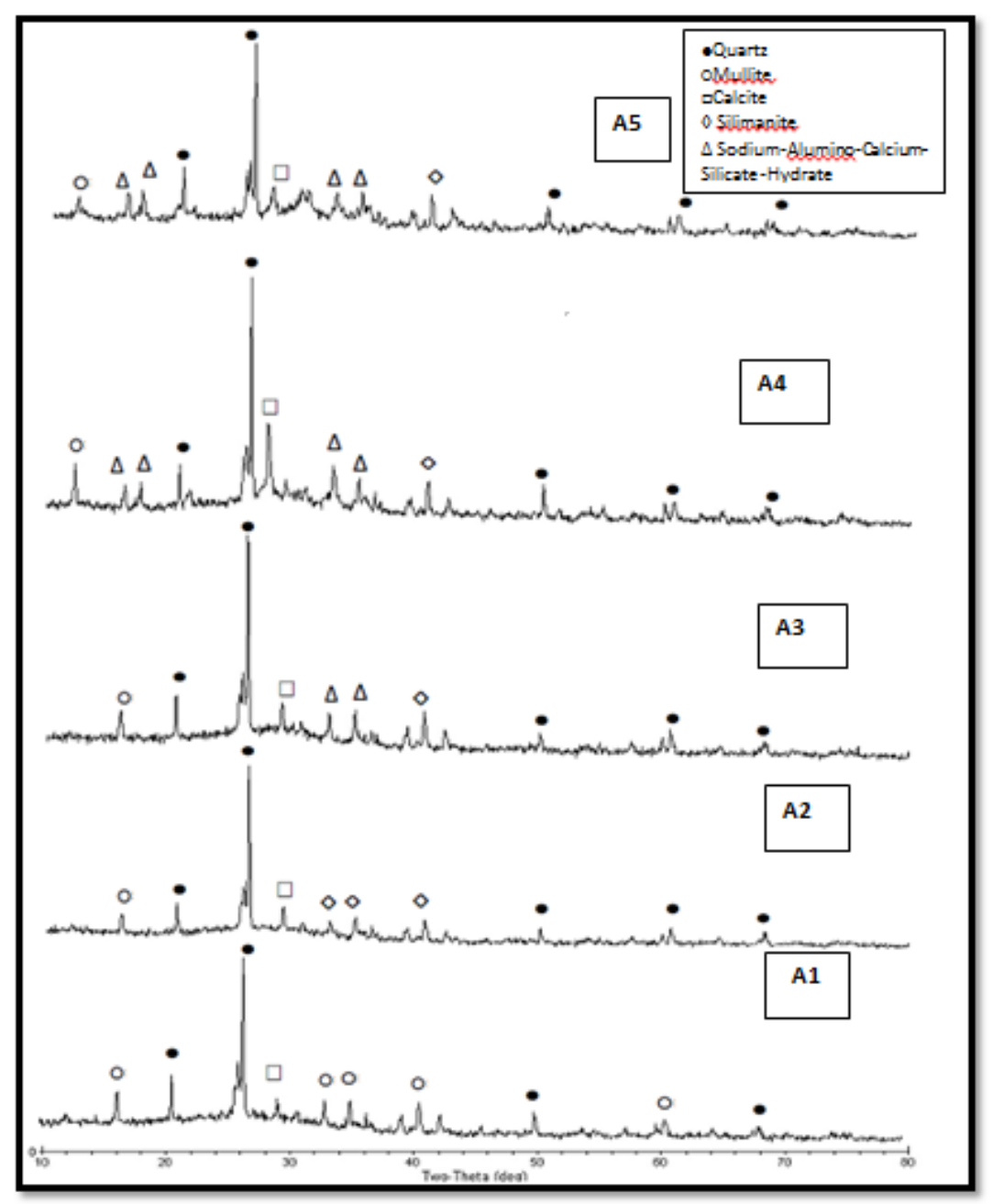

Fig. 6. Effect of variation of sodium hydroxide on $x$ ray diffraction graphs of fly ash slag based geopolymer composite

\section{Scanning Electron Microscopy/Energy Dispersive X-Ray Analysis}

As has been discussed in the XRD analysis section the concentration of $\mathrm{NaOH}$ ions in the activator solution has an effect on the progress of the various stages of geopolymerisation. This is clearly reflected in the sem images. SEM images of the A1 mix clearly point to the fact that gel structure is disjointed in nature leaving multiple number of voids in the structure, a few unreacted fly ash particles can also be seen. The lack of adequate $\mathrm{OH}$-ions resulted in the incomplete dissolution of $\mathrm{Si}, \mathrm{Al}$ and $\mathrm{Ca}$ species thus a lot of inactivated fly ash and slag particles can be seen. In the A2 mix we can see an improved and more cohesive microstructure with lesser number of voids. 


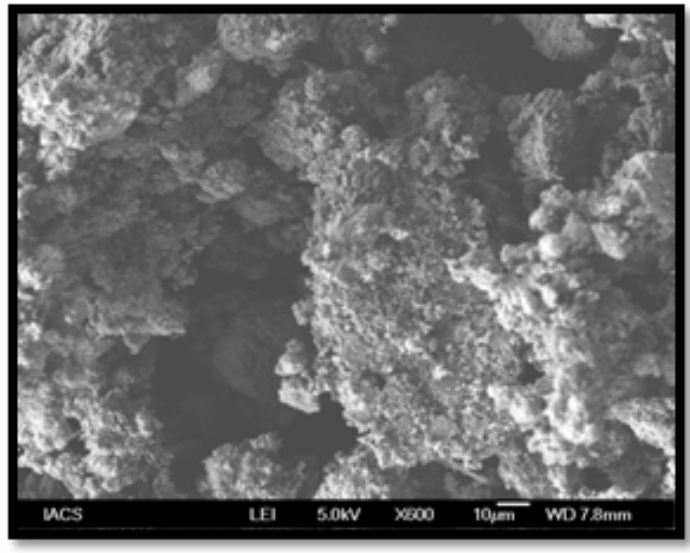

Fig. 7a. A1 mix SEM IMAGE

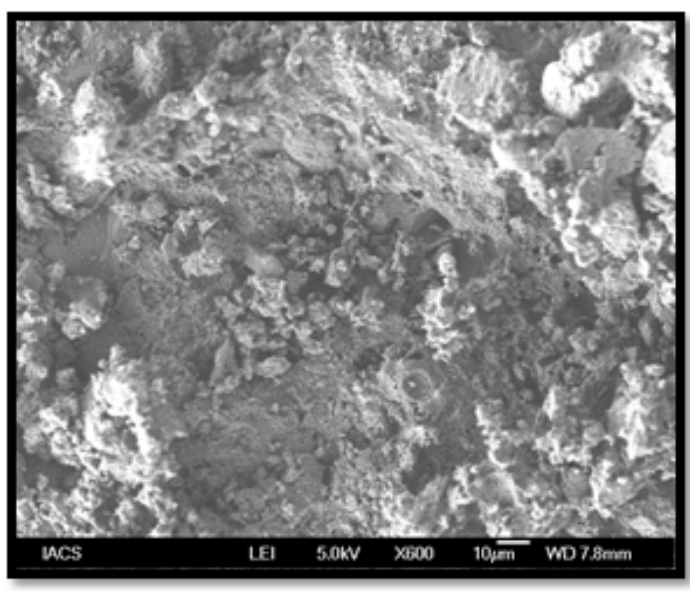

Fig. 7c. A2 mix SEM IMAGE

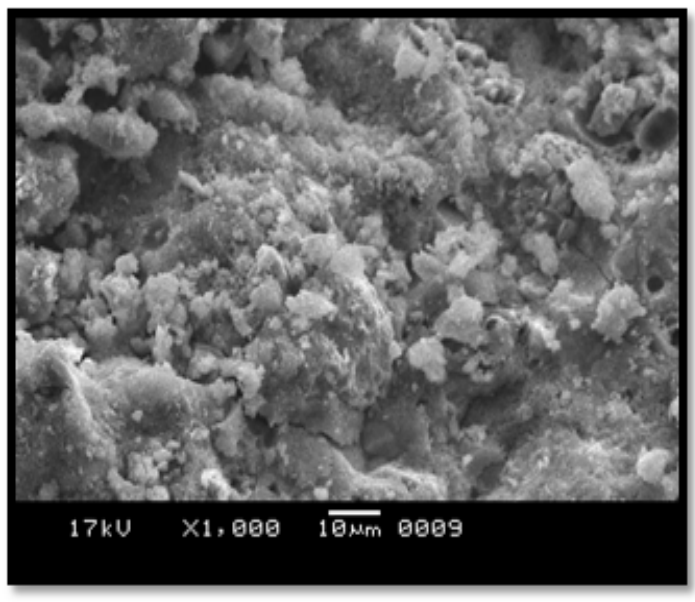

Fig. 7e. A3 mix SEM IMAGE

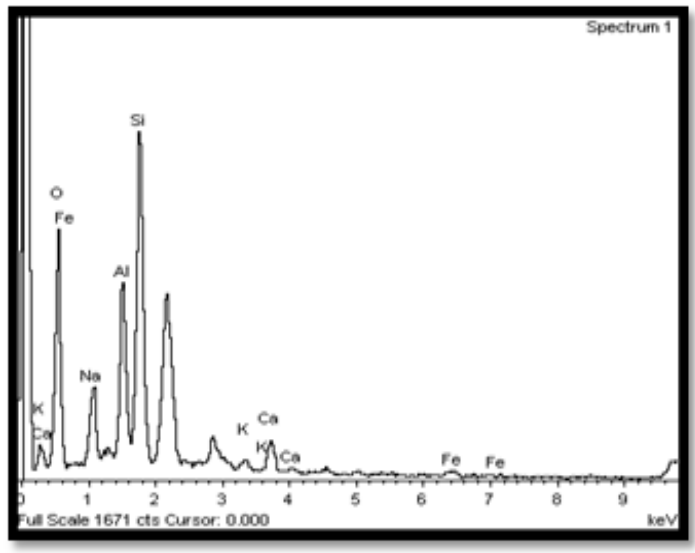

Fig. 7b. A1 mix EDAX Results

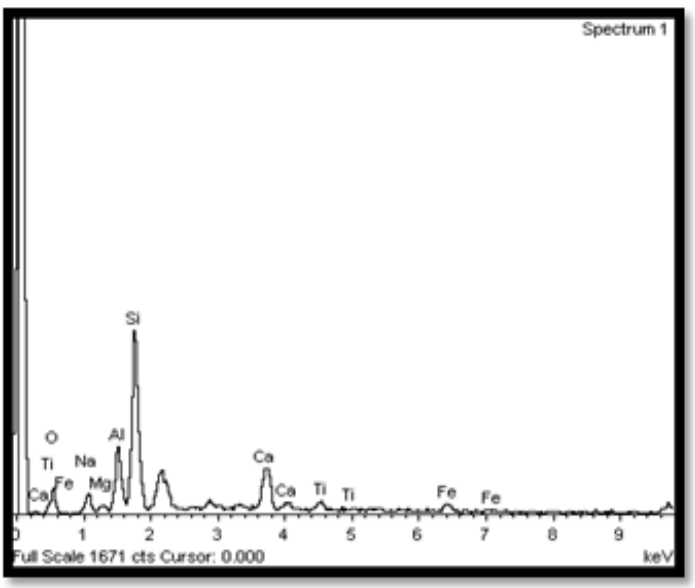

Fig. 7d. A2 mix SEM IMAGE

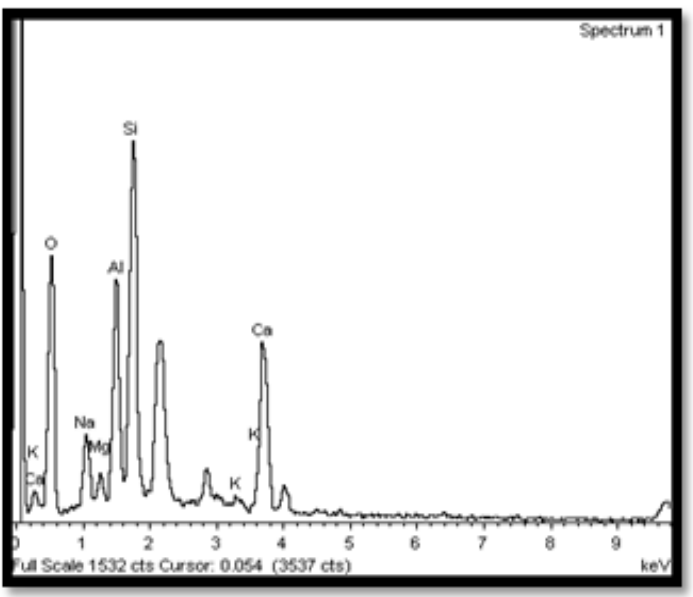

Fig. 7f. A3 mix EDAX Result 


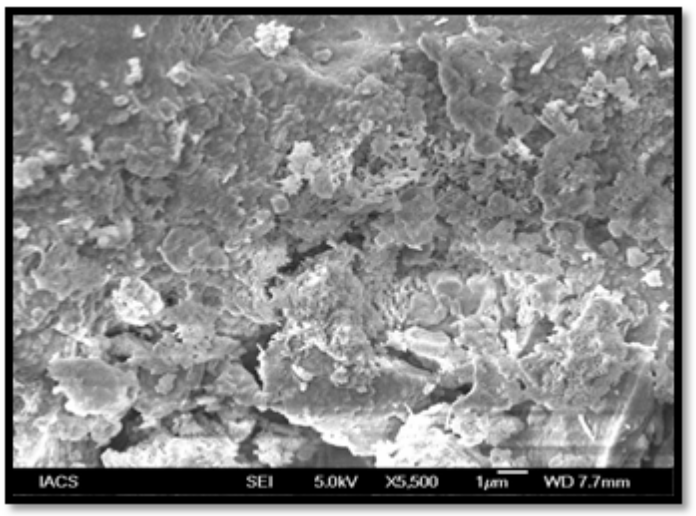

Fig. 7g. A4 mix SEM IMAGE

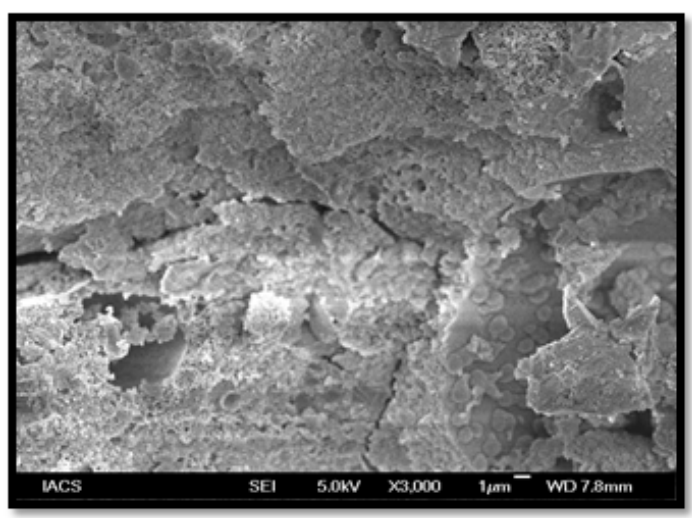

Fig. 7i. A5 mix SEM IMAGE

But the gel matrix has still not been properly formed, unreacted fly ash slag particles still remain. In A3 mix we can see that relative to other samples more gel formation has taken place and a few products of precipitation can be seen. The calcium content also rises in this mix compared to $\mathrm{A} 1$ and $\mathrm{A} 2$. As the alkali content is increased upto $10 \%$ of total weight in the A4 sample, cracks can be seen to develop. From the EDAX analysis and the XRD analysis the gel matrix consists of calcium silicate hydrate gel as well as a hybrid alumino-calcium-silicate gel. The percentage of $\mathrm{Ca}$ ions shown in the edax analysis also decreases as leaching of calcium ions are inhibited by high $\mathrm{pH}$. But as the alkali content is increased to $12 \%$ there is deterioration in the gel matrix as cracks become visible. As there is excess $\mathrm{OH}^{-}$ions it affects the geopolymerisation reaction in a negative manner. The calcium silicate hydrate is also not able to form. Due to the abundant $\mathrm{OH}^{-}$ions dissolution occurs very quickly and flash setting takes place and this impedes the geopolymerisation reaction to a great

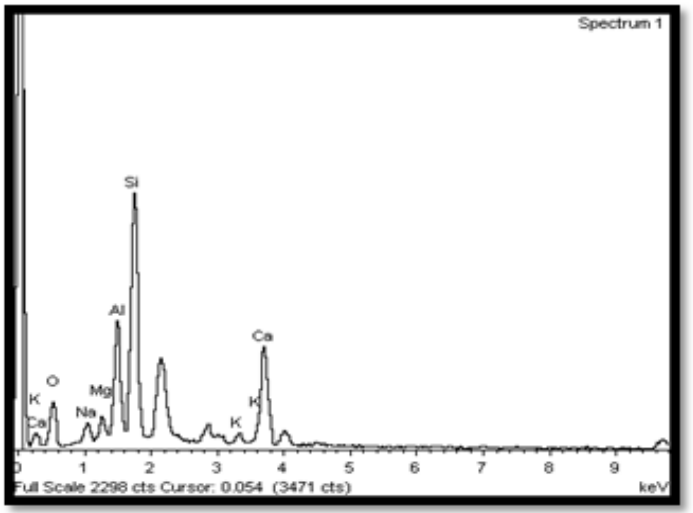

Fig. 7h. A4 mix EDAX Results

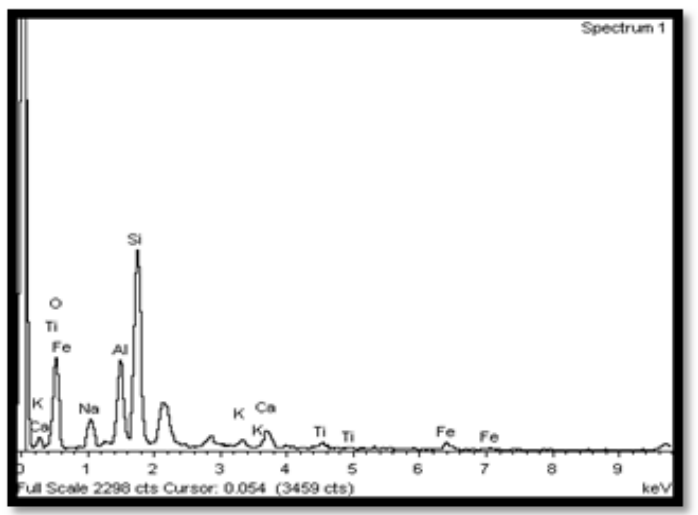

Fig. 7j. A5 mix EDAX Results

extent resulting in the formation of cracks along the gel matrix.

\section{FTIR Analysis}

On analyzing the FTIR data it was seen from fig 8 that there was a broad hump in the range of $3300 \mathrm{~cm}^{-1}-3700 \mathrm{~cm}^{-1}$ in all the samples which can be attributed to the $\mathrm{OH}^{-}$group, the hump was wider in case of the A2, A3 and A4 sample. There was also a sharp peak intensity at $3704-3709 \mathrm{~cm}^{-1}$ which is due to the stretching vibration of $\mathrm{OH}$ group. The hump noticed from 977 to $1134 \mathrm{~cm}^{-1}$ for $\mathrm{A} 2$ and A3 mix due to the asymmetric stretching vibration of Si-O-Si evolves into a sharp peak for A1 and A5 which signifies the incomplete geopolymerisation process due to both excess and inadequate $\mathrm{OH}^{-}$ groups respectively. The peaks at 470 to $480 \mathrm{~cm}^{-1}$ denoting bending Si-O-Si group vibration seems to shift to a lower wavenumber for A1 and A5 samples. Peaks due to $\mathrm{C}-\mathrm{S}-\mathrm{H}$ gel can be seen at 880 to $900 \mathrm{~cm}^{-1}$ which is a comparatively lower wave number as the C-S-H gel is normally seen at 900 to $950 \mathrm{~cm}^{-1}$ for alkali activated slag samples. 
This is due to the fact that as the samples are thermally cured the aluminosilicate gel is functioning as the major gel network with $\mathrm{C}-\mathrm{S}-\mathrm{H}$ functioning as the minor one. The transmittance data in general points to the fact that the absorption values of the various functional groups has increased with increase with increase in sodium hydroxide concentration upto the optimum level of $8 \%$ thus signifying higher order of polymerization taking place in the $\mathrm{A} 2$ and $\mathrm{A} 3$ sample.

\section{Zeta Potential}

Zeta potential is an important factor governing electrostatic interactions in particle dispersions and, as such, it plays a key role in understanding the stability of colloidal dispersions. It is used in formulating optimal solutions of suspensions and emulsions and can also be used to build a long-term stability prediction model 26,27,28. It has been known to have an effect on the microstructure of geopolymer specimens ${ }^{29}$. Analytical techniques like XRD,SEM and its relationship with hardeed and fresh properties of concrete has already been conducted by the authors as well as other resarchers. ${ }^{30}$ In the current study a relationship has been tried to establish between zeta potential and other mechanical properties of the test specimens. The zeta potential values of the fly ash and slag raw materials were $-9.44 \mathrm{mV}$ and $-13.9 \mathrm{mV}$ respectively. The negative zeta potential signified that the silicates $\left(-\mathrm{O}-\mathrm{SiO}_{2}-\right)$ and aluminates (-O-AIO-) were present abundantly near the surface. The negative zeta potential of the mix's A1, A2, A3, A4, A5 is seen to increase with addition of sodium hydroxide content. As the leaching rate of silicates and aluminates depends upon the rate of dissolution which increases with the addition of sodium hydroxide solution, it can be said that the negative zeta potential leads to faster dissolution. This aligns with fact that A5 having the highest negative zeta potential values had experienced flash setting which can be attributed to the higher rate of dissolution. The XRD results also points to the fact that the gel formation increased with higher negative zeta potential values as the peaks of aluminosilicate and calcium aluminosilicate had higher peaks. The higher zeta potential of the A5 mix could also be a result of the additional $\mathrm{OH}$ - ions of the mix which had negative impact on the structure of the geopolymer.

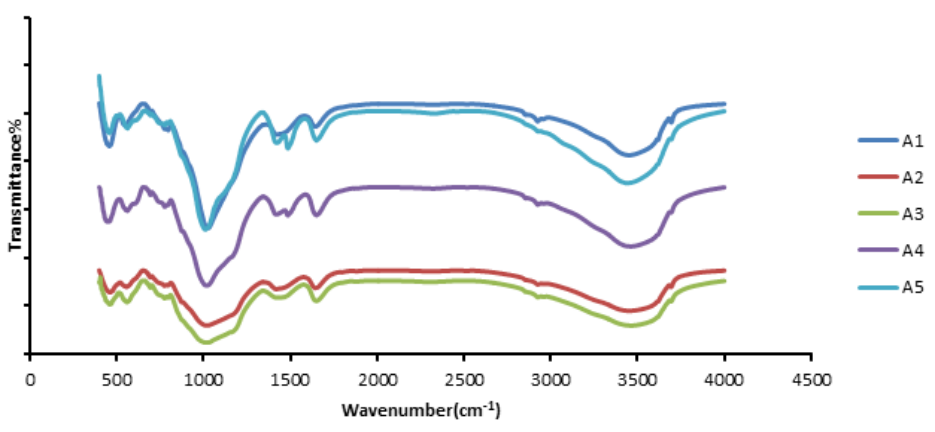

Fig. 8. Effect of variation of sodium hydroxide on FTIR spectra of fly ash slag based geopolymer composite

Variation of Zeta Potential vs Percentage of

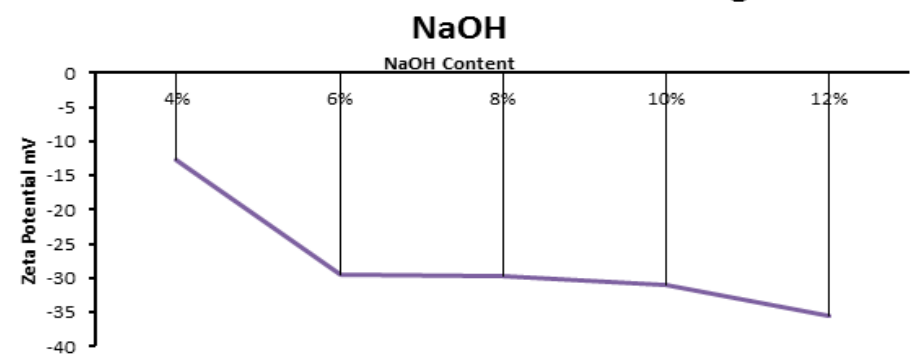

Fig. 9. Effect of variation of sodium hydroxide on zeta potential of fly ash slag based geopolymer composite 
The electrical conductivity of the samples are seen to increase with the addition of the sodium hydroxide solution. The conductivity recorded for the A1 sample with $4 \% \mathrm{NaOH}$ is the lowest at .0569 $\mathrm{mS} / \mathrm{cm}$, the value increases significantly for A2 sample at $.123 \mathrm{mS} / \mathrm{cm}$. The conductivity for the A3, A4, A5 samples continue to increase with recorded values of $.172 \mathrm{mS} / \mathrm{cm}, .314 \mathrm{mS} / \mathrm{cm}$ and $.345 \mathrm{mS} / \mathrm{cm}$ respectively. The increase of conductivity of the samples can be attributed to the formation of denser microstructure with increase in sodium hydroxide as visible in the sem images. The increase in ions as well as ionic mobility due to the greater leaching of $\mathrm{Si}^{+}, \mathrm{Al}^{+}$ions may also influence the conductivity of the samples.

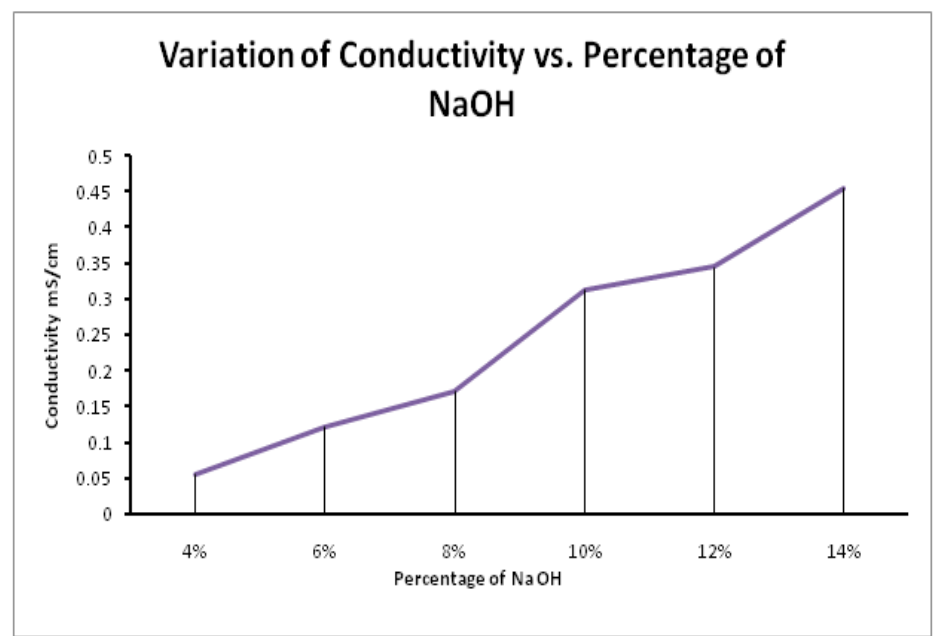

Fig. 10. Effect of variation of sodium hydroxide on conductivity of fly ash slag based geopolymer composite

\section{CONCLUSION}

1) Experimental results given in Fig. $6 a$ to $6 e$ and Fig. 7a to $7 e$ indicated the co-existence of calcium silicate gel and aluminium silicate gel.

2) The addition of sodium hydroxide up to a concentration of $8 \%$ results in the formation of a extremely dense and more compact microstructure, and provided higher value of other mechanical properties e.g compressive strength, bulk density, apparent porosity and water absorption values along with ultrasonic pulse velocity values. This may be attributed to the increase of rate of dissolution with increase in sodium hydroxide content, which leads to the leaching of $\mathrm{Si}^{+++}, \mathrm{Al}^{+++}$and $\mathrm{Ca}^{++}$ions. However, excess sodium hydroxide ( more than $8 \%$ ) leads to flash setting and does not allow one to have a proper workable mix.It also impedes the formation of calcium silicate hydrate gel. As a result lower strength was observed as can be seen in Figure 1.

3) The zeta potential value as well as electrical conductivity values increases with the increase in sodium hydroxide concentration. This can be attributed to the greater ionic mobility generated in the specimens due to the higher rate of leaching of $\mathrm{Si}^{+++}, \mathrm{Al}^{+++}$ions due to the increase of sodium hydroxide content.

\section{ACKNOWLEDGEMENT}

We are deeply grateful to Jadavpur University for providing us with the necessary facilities required for carrying out the relevant research work.

\section{REFERENCES}

1. Bakharev. T.; Sanjayan, J G.; Cheng, Y-B.; Alkali activation of Australian slag cements. Cem Concr Res., 1999, 29(1),113-20.

2. Van. Jaarsveld. J. G.S.; Van. Deventer. J. S. J.;
Effect of the alkali metal activator on theproperties of fly ash-based geopolymers. Ind Eng Chem Res., 1999, 38, 3932-41.

3. Roy, DM.; Alkali-activated cements: 
opportunities and challenges. Cem Concr Res 1999, 29(2), 249-54.

4. Palomo. A,; Grutzeck, MW.; Blanco, MT.; Alkali-activated fly ashes: A cement for the future. Cem Concr Res., 1999, 29(8), 1323-9.

5. Gruskovnjak, A.; Lothenbach, B.; Holzer, L.; Figi, R.; Winnefeld F. Hydration of alkali-activated slag: comparison with ordinary Portland cement. Adv Cem Res., 2006, 18(3),119-28.

6. Sindhunata, Provis JL.; Lukey, GC.; Xu H, Van.; Deventer, J. S. J.; Structural evolution offly ash based geopolymers in alkaline environments. Ind Eng Chem Res., 2008, 47(9), 2991-9.

7. Van, Deventer, J.S.J.; Provis, J.L.; Duxson, P.; Technical and commercial progress in the adoption of geopolymer cement. Min Eng., 2012, 29, 89-104.

8. Van, Deventer, J. S. J.; Provis, J. L.; Duxson P.; Brice, D.G.; Chemical research and climate change as drivers in the commercial adoption of alkali activated materials. Waste Biomass Valor., 2010, 1, 145-55.

9. Davidovits-Geopolymer, J.; cements to minimize carbon-dioxide greenhousewarming-M. Moukwa, S. L. Sarkar, K. Luke (Eds.), Ceramic transactions cement-based materials: present, future, and environmental aspects, The American Ceramic Society, Westerville., 1993, 165-181.

10. Somna, K.; Jaturapitakkul, C.; Kajitvichyanukul. P.; P. Chindaprasirt-NaOH-activated ground fly ash geopolymer cured at ambient temperature Fuel., 2011, 90 (6), 2118-2124.

11. Palomo, A.; Grutzeck, M.W.; BlancoAlkali, M. T.; activated fly ashes: a cement for the future Cem. Concr. Res., 1999, 29 (8) 323-1329.

12. Kumar, Sanjay, Rakesh Kumar, and S. P.Mehrotra. "Influence of granulated blast furnace slag on the reaction, structure and properties of fly ash based geopolymer." Journal of materials science., 2010, 45(3) 607-615.

13. Chindaprasirt, P., T. Chareerat, and VuteSirivivatnanon. "Workability and strength of coarse high calcium fly ash geopolymer." Cement and Concrete Composites., 2007, 29(3) 224-229.

14. Thakur, Ravindra N.; and Somnath. Ghosh.;"Effect of mix composition on compressive strength and microstructure of fly ash based geopolymer composites." ARPN Journal of Engineering and Applied Sciences., 2009, 4(4) 68-74.

15. Panias. D.; Giannopoulou, I. P.; Perraki, T.; Effect of synthesis parameters on the mechanical properties of fly ash-based geopolymers Colloids Surf A., (2007), 301
(1-3), 246-254

16. Somna, K; Jaturapitakkul, C.P.Kajitvichyanukul.; Chindaprasirt, $\mathrm{P} ; \mathrm{NaOH}$-activated ground fly ash geopolymer cured at ambient temperature Fuel., 2011, 90 (6), 2118-2124.

17. Palomo, A.; Grutzeck,M. W.; BlancoAlkali, M.T.; activated fly ashes: a cement for the future Cem. Concr. Res., (1999), 29(8), 323-1329

18. Hunter R. J.; Introduction to modern colloid science. Oxford, UK: Oxford Science Publications; 1993.

19. Everett, D. H.; Basic principles of colloid science. London, UK: The Royal Society of Chemistry; 1994.

20. Zuhua, Z. ; Xiao,Y.; Huajun, Z.; Yue, C.; Role of water in the synthesis of calcined kaolin-based geopolymer Appl Clay Sci, 43 (2) (2009), pp. 218-223.

21. Van, Deventer, J. S. J.; Provis, J. L.; Duxson, P.; Luckey,G.C.;-'Reaction mechanisms in the geopolymeric conversion of inorganic waste to useful products" -J. Hazard.Mater., 2007, A139, 506-513.

22. Lee, W. K.W.; Van, Deventer, J.S.J.;-"The effect of ionic contaminants on the early-age properties of alkali-aktivated fly ash based cements-Cement Concrete Res., 2002, 32, 577-584.

23. Yip, C.K.; Lukey, G. C.; Provis, J. L.; Van, Deventer, J. S. J.; -Effect of calcium silicate sources on geopolymerisation-Cem. Concr. Res., 2008, 38, 554-564.

24. Shaw D. J.; Introduction to colloid and surface chemistry. London, UK: Butterworth Heinemann; 1992.

25. Hunter R. J.; Introduction to modern colloid science. Oxford, UK: Oxford Science Publications; 1993.

26. Kumar, Sanjay, Rakesh Kumar, and S. P. Mehrotra.; "Influence of granulated blast furnace slag on the reaction, structure and properties of fly ash based geopolymer." Journal of materials science., 2010, 45(3) 607-615.

27. Van, Deventer, J. S. J.; Provis, J. L.; Duxson, P.; Luckey, G.C.;-"Reaction mechanisms in the geopolymeric conversion of inorganic waste to useful products" -J. Hazard.Mater., 2007, A139, 506-513

28. Lee, W. K.W.; Van, Deventer, J.S. J.; -"The effect of ionic contaminants on the early-age properties of alkali-aktivated fly ash based cements-Cement Concrete Res., 2002, 32, 577-584.

29. Revathi, T.; Jeyalakshmi, R.; Rajamane N. P.; Sivasakthi, M.; Evaluation of the Role of Cetyltrimethylammoniumbromide (CTAB) and Acetylenic Glycol (AG) Admixture on fly ash Based Geopolymer. Orient. J. Chem ., 2017, 33(2).

30. Sivasakthi. M.; Jeyalakshmi, R.; Rajamane N. P.; Revathi T. Use of Analytical Techniques for the Identification of the Geopolymer Reactions. Orient. J. Chem., 2017, 33(4). 